Revista Destaques Acadêmicos, Lajeado, v. 10, n. 1, 2018. ISSN 2176-3070

DOI: http://dx.doi.org/10.22410/issn.2176-3070.v10i1a2018.1167

http://www.univates.br/revistas

\title{
AGROINDÚSTRIAS FAMILIARES FABRICANTES DE PRODUTOS CÁRNEOS SUÍNOS: PRINCIPAIS DIFICULDADES PERANTE A LEGISLAÇÃO VIGENTE
}

\author{
Neiton Bittencourt Perufo ${ }^{1}$, Lucia de Moraes Batista ${ }^{2}$, Nilo Kern Cortez ${ }^{3}$
}

Resumo: A realização de uma pesquisa exploratória, através do preenchimento de questionários junto aos responsáveis de agroindústrias familiares fabricantes de produtos cárneos suínos, teve o objetivo de verificar as principais dificuldades encontradas no momento da regularização e rotina de trabalho perante a legislação vigente a níveis sanitários, ambientais e tributários, coletando também informações sobre os custos de cada nível. Foram realizadas entrevistas em vinte agroindústrias distribuídas dentro dos limites de municípios que compõem o regional da Emater/RSAscar de Lajeado/RS. Foram encontradas diversas dificuldades, tanto no momento da regularização do estabelecimento, como na rotina de trabalho, bem como, a variação de custos desembolsados entre cada estabelecimento.

Palavras-chave: Custos. Ambiental. Tributário. Sanitário.

\section{INTRODUÇÃO}

Após a instalação de algumas famílias de imigrantes no Estado do Rio Grande do Sul, sendo em sua maioria constituída por pequenos grupos familiares, formaram-se minifúndios rurais em todo o interior do estado, os quais hoje são conhecidos como agricultores familiares. Através dos anos, a culinária típica oriunda dessas famílias foi caracterizada pela elaboração de produtos denominados "coloniais", e que através dos tempos tornou-se uma

1 Tecnólogo em Alimentos e Pós Graduado em Tecnologia de Alimentos na Unidade Integrada Vale do Taquari de Ensino Superior (UNIVATES). Extensionista Rural de Nível Superior Social da Emater/RS-Ascar. Email: nperufo@emater.tche.br

2 Engenheira de Alimentos, Doutora em Engenharia e Ciência de Alimentos. Professora de Ensino Básico, Técnico e Tecnológico no Instituto Federal de Educação, Ciência e Tecnologia do Rio Grande do Sul - Câmpus Bento Gonçalves. Email: lucia.batista@bento.ifrs.edu.br

3 Engenheiro Agrônomo, Consultor técnico do setor de agroindústria da COOPATER - Cooperativa dos Profissionais da Assistência Técnica e Extensão Rural. Email: nilokeco@yahoo.com.br 
referência para qualquer consumidor, sendo sinônimo de um produto de sabor diferenciado com características específicas.

Devido à grande demanda consumista, a oportunidade de agregar valor à matéria-prima e principalmente às exigências das fiscalizações, que tem por finalidade prezar pela qualidade na fabricação dos produtos coloniais, tanto nos aspectos sanitários, ambientais e tributários, viu-se a necessidade da evolução tecnológica na elaboração desses produtos. Desde então, o apoio de entidades como a Emater/RS-Ascar que contribui para a qualificação de produtores rurais e principalmente para a regularização de agroindústrias familiares que melhor atendessem a demanda produtiva, foram de suma importância para que esse avanço pudesse acontecer. Nos últimos anos a procura pela regularização destes estabelecimentos tomou grandes proporções. Segundo Santos (2006) isso se deve a uma tendência que está amparada pelo conceito de agregação de valor, onde alguns estudos apontam para a necessidade de alternativas de comercialização a partir da transformação de matérias-primas primárias em produtos finais com maior valor agregado.

As exigências dos órgãos de fiscalização estão amparadas pela legislação vigente e podem ser destacadas por três níveis: o ambiental, o sanitário e o tributário. Esses três segmentos são muito importantes para regrar o produtor rural que possui em sua propriedade a fabricação ilegal de alimentos processados, principalmente os que elaboram produtos de origem animal, pois estes são os que demandam de uma atenção especial, devido aos vários riscos patogênicos que podem ser transmitidos do produto para o consumidor, bem como, o tratamento de resíduos remanescentes da fabricação que prejudicam de maneira drástica o meio ambiente. Segundo Kuhn (2012), “[...] O Brasil tem 32 mil agroindústrias familiares, de acordo com uma estimativa do governo federal, e mais da metade ainda estão irregulares. Pela média, dez famílias estão envolvidas com cada indústria, ou seja, 320 mil pessoas trabalham nesse tipo de negócio.". Com esses resultados vemos que a regularização de novas agroindústrias familiares é um passo extremamente importante para a evolução da cadeia alimentícia, prevendo que esta realidade está muito próxima de se concretizar, devido à possibilidade de uma flexibilização da legislação agroindustrial familiar.

O presente trabalho tem o objetivo da realização de uma pesquisa acadêmica de forma exploratória, através de entrevistas realizadas junto aos responsáveis de agroindústrias familiares, fabricantes de produtos cárneos suínos, com o intuito de verificar as principais dificuldades e os custos encontrados nestes estabelecimentos, no momento da sua regularização e rotina de trabalho, perante as legislações vigentes a níveis sanitários, ambientais e tributários. 


\section{MATERIAIS E MÉTODOS}

Este trabalho foi elaborado a partir dos resultados das entrevistas realizadas através da visitação em vinte agroindústrias distribuídas dentro dos limites de municípios que compõem o regional da Emater/RS-Ascar de Lajeado/RS. Essas empresas representam $69 \%$ de um total de 29 que fabricam produtos cárneos suínos, e que estão inseridas nos limites deste regional. Desses vinte estabelecimentos, três locais além de beneficiarem a matériaprima, também realizam a matança desses animais.

Desse modo, foi elaborado um questionário com perguntas sobre as principais dificuldades que as agroindústrias tiveram no momento da regularização e as dificuldades que estão tendo na rotina de trabalho perante a legislação, nos aspectos ambientais, sanitárias e tributárias, levantando também informações sobre os custos relacionados a esses segmentos.

Em um primeiro momento, essas questões foram respondidas de forma descritiva, onde eram realizadas ao responsável do estabelecimento. As perguntas foram respondidas de forma despojada, obtendo liberdade de diálogo entre entrevistador e entrevistado, isso com o intuito de facilitar a linguagem coloquial e a compreensão da verdadeira situação do local. Segundo Freire (1983), o entendimento da significação dos signos linguísticos deste camponês implica na compreensão do contexto em que se gera a convicção que foi expressa pelos signos linguísticos, isso significa que devemos primeiramente ter conhecimento da linguagem que o produtor rural está adaptado, o seu modo de vida, seus costumes, sua cultura, sua maneira em geral de viver e ver o mundo, para que só assim possamos ter capacidade de interpretar de maneira convicta o contexto real da sua situação.

No cabeçalho do questionário foram solicitadas algumas informações sobre os estabelecimentos, isso para que fosse possível conhecer os empreendimentos, questões como: nome da empresa, situação tributária, proprietário(s), grau de escolaridade, responsabilidade técnica, endereço, contato, classificação do estabelecimento, tempo de existência, se recebe assistência técnica, tamanho da agroindústria, órgão fiscalizador sanitário, produtos fabricados e registro de marca. Estas informações tiveram grande importância para a compilação, bem como, na conclusão deste trabalho.

Depois de concluída as vinte entrevistas, foi realizada a interpretação dessas respostas descritivas, onde as mesmas foram tabuladas de forma objetiva, de maneira que fosse possível ordenar as que mais tiveram sentido umas com as outras, isso para facilitar a tabulação dos resultados, obtendo o mesmo fundamento e a mesma base de argumento, porém com linguagem e formas de expressões diferentes. Foi realizado também a tabulação dos custos que as empresas tiveram nos diferentes segmentos e aspectos de avaliação deste trabalho. 


\section{RESULTADOS E DISCUSSÕES}

Embora cada empresa tenha seu próprio método de trabalho e, por consequência, seus próprios resultados, alguns entraves identificados podem dificultar o funcionamento destes locais. Serão apresentadas as respostas das principais dificuldades encontradas pelos proprietários das agroindústrias familiares, no momento da regularização e no atual trabalho, conforme as regras da legislação vigente nos níveis sanitários, ambientais e tributários, sendo explanados também os custos de cada segmento.

Além disso, cabe ressaltar que uma série de características provenientes das unidades familiares pode interferir nos resultados obtidos nesta pesquisa. Foram extraídos do cabeçalho resultados importantes para a realização de um comparativo no momento da conclusão, como: Grau de escolaridade, recebimento de assistência técnica, tempo de existência e profissionalização Tabelas 1, 2, 3 e 4 .

Tabela 1: Grau de escolaridade dos responsáveis de cada agroindústria entrevistada

\begin{tabular}{l|c}
\hline \multicolumn{1}{c|}{ Alternativas } & $\mathbf{N}^{\circ}$ de entrevistados \\
\hline Até a $4^{\circ}$ Ens. Fund. & 3 \\
\hline $5^{\circ}$ e $7^{\circ}$ Ens. Fund. & 8 \\
\hline Ens. Fund. Completo & 2 \\
\hline Ens. Médio Incompleto & 1 \\
\hline Ens. Médio Completo & 3 \\
\hline Ens. Superior Incompleto & 2 \\
\hline Ens. Superior completo & 1 \\
\hline
\end{tabular}

Fonte: Dados elaborados pelo autor.

Através destes resultados, na Tabela 1 podemos analisar que $55 \%$ dos responsáveis por esses estabelecimentos não concluíram o ensino fundamental. Isso mostra o baixo grau de estudo dessas pessoas que estão administrando seus próprios estabelecimentos. O grau de escolaridade dos responsáveis pode interferir na agregação de conhecimentos, para melhor interpretar as questões burocráticas que essas pessoas irão se deparar no decorrer dos trabalhos em seus estabelecimentos. 
Tabela 2: Assistência técnica na agroindústria, segmentos: sanitários, tributários e ambientais

\begin{tabular}{l|c}
\hline \multicolumn{1}{c|}{ Alternativas } & $\mathbf{N}^{\circ}$ de entrevistados \\
\hline Não recebe & 4 \\
\hline Responsável Técnico & 11 \\
\hline EMATER & 2 \\
\hline Fiscais & 1 \\
\hline Outros & 2 \\
\hline
\end{tabular}

Fonte: Dados elaborados pelo autor.

$\mathrm{Na}$ Tabela 2, nota-se que a maioria dos estabelecimentos recebe de alguma forma orientações nos três segmentos da pesquisa, tanto por parte da Emater/RS-Ascar, do responsável técnico, do fiscal ou de profissionais da área.

Tabela 3: Tempo de existência no mercado de cada empresa

\begin{tabular}{l|c}
\hline \multicolumn{1}{c|}{ Alternativas } & $\mathbf{N}^{\mathbf{0}}$ de entrevistados \\
\hline Até 5 anos de existência & 5 \\
\hline De 6 a 10 anos de existência & 9 \\
\hline De 11 a 15 anos de existência & 3 \\
\hline Acima de 15 anos de existência & 3 \\
\hline
\end{tabular}

Fonte: Dados elaborados pelo autor.

Na Tabela 3, fica claro que a grande maioria dos estabelecimentos já possui uma boa experiência de mercado, $75 \%$ possuem tempo de existência no mercado maior que 6 anos, envolvendo durante esse período as questões de regularização e o comércio legal de seus produtos.

Tabela 4: Cursos realizados pelos responsáveis das agroindústrias

\begin{tabular}{l|c}
\hline \multicolumn{1}{c|}{ Alternativas } & $\mathbf{N}^{\mathbf{0}}$ de entrevistados \\
\hline Não Possui & 4 \\
\hline Cursos Básicos na área de alimentos & 13 \\
\hline Outros cursos & 3 \\
\hline
\end{tabular}

Fonte: Dados elaborados pelo autor.

Quanto aos cursos, na Tabela 4, nota-se que 4 estabelecimentos não possuem nenhum curso na área de alimentos, outros 3 locais possuem cursos em outras áreas que não a de alimentos e a maioria dos estabelecimentos possui somente cursos básicos na área de alimentos, esses cursos se resumem em treinamentos de boas práticas de fabricação, no Centro de Formação de 
Fazenda Sousa (CEFAS - Emater/RS-Ascar, Caxias do Sul/RS) curso I e II de processamento de carne suína no Centro de Treinamento de Agricultores de Nova Petrópolis (CETANP-EMATER/ASCAR - Nova Petrópolis/RS) e outros cursos disponibilizados pelo Serviço Nacional de Aprendizagem Rural (SENAR/RS) e pela Unidade Integrada Vale do Taquari de Ensino Superior (UNIVATES - Lajeado/RS).

\subsection{Segmento Ambiental}

No segmento ambiental foram encontradas três empresas registradas via Secretária Estadual do Meio Ambiente (SEMA) e dezessete empresas registradas pela Secretaria Municipal do Meio Ambiente (SMMA) de seus municípios de origem.

Nas principais dificuldades impostas pela legislação ambiental no momento da regularização das agroindústrias, obtiveram-se os seguintes resultados, Tabela 5 .

Tabela 5: Principais dificuldades impostas pela legislação ambiental no momento de regularizar as agroindústrias

\begin{tabular}{l|r|r|r|r}
\hline Alternativas & SEMA & SMMA & $\mathbf{N}^{\mathbf{0}}$ total & \% total \\
\hline Não houve dificuldades & 1 & 10 & 11 & 55 \\
\hline Desinformação da fiscalização & 0 & 4 & 4 & 20 \\
\hline Excesso de exigência & 1 & 3 & 4 & 20 \\
\hline Custo elevado do registro & 1 & 0 & 1 & 5 \\
\hline
\end{tabular}

Fonte: Dados elaborados pelo autor.

Com esses resultados podemos observar que mais da metade dos estabelecimentos não teve nenhuma dificuldade junto ao órgão ambiental para efetivar seu registro. Alguns locais que foram cadastrados junto a SMMA alegaram a falta de informações, isso pode ser decorrente a pouca experiência de alguns municípios junto a este segmento, devido ao seu recente registro de descentralização ambiental. Quanto ao excesso de exigências como a cobrança demasiada de reformas, é importante considerar que os fiscais ambientais são competentes para a realização deste serviço, onde essas cobranças têm por objetivo evitar ou melhorar os controles de resíduos provenientes dos estabelecimentos sem prejudicar o meio ambiente. Outra informação junto a essa questão, era a exigência da fiscalização para que fosse feita a contratação de um profissional por parte da empresa (engenheiro químico ou geólogo) e que este, se responsabilizasse pela Licença Prévia, Licença de Instalação e a Licença de Operação. Essa cobrança não procede, pois não existe nenhuma lei que exija a contratação de um destes dois tipos de profissionais, a única exigência é que tenha um responsável técnico que emita a Anotação de Responsabilidade 
Técnica (A.R.T.) conforme consta no inciso II do Art. $3^{\circ}$ da Resolução ${ }^{\circ}$ 385, (RIO GRANDE DO SUL, 2006) e que em seu currículo profissional seja permitido assumir esta responsabilidade. Já a única empresa que destacou o custo elevado no registro, deve-se considerar que este valor pode variar conforme o órgão ambiental responsável, bem como, o seu município de origem.

Aproveitando a mesma questão, as empresas foram indagadas sobre os custos referentes aos registros ambientais, os resultados estão apresentados na Tabela 6.

Tabela 6: Custos referentes à questão ambiental no momento de regularizar as agroindústrias

\begin{tabular}{l|r|r|r|r}
\hline Alternativas & SEMA & SMMA & $\mathbf{N}^{\mathbf{0}}$ total & \% total \\
\hline Não sabe & 1 & 9 & 10 & 50 \\
\hline Até R\$ $1.000,00$ & 1 & 4 & 5 & 25 \\
\hline Entre R\$ $1.000,00$ e R $\$ 2.000,00$ & 1 & 1 & 2 & 10 \\
\hline Entre R\$ 2.000,00 e R $\$ 3.000,00$ & 0 & 2 & 2 & 10 \\
\hline Acima de R\$3.000,00 & 0 & 1 & 1 & 5 \\
\hline
\end{tabular}

Fonte: Dados elaborados pelo autor.

Quanto aos custos, é possível observar que metade dos estabelecimentos desconhece o quanto foi gasto no registro, isso demonstra a falta de preparo administrativo das empresas para controlar e registrar estes custos. Os demais estabelecimentos que alegaram diferentes valores se mostraram competentes em manter um controle registrado do que foi gasto no princípio dos seus trabalhos, a diferenciação desses valores demonstra que pode ocorrer uma variação, conforme o órgão ambiental responsável e os municípios envolvidos na pesquisa.

Para o momento atual, foi perguntado qual estava sendo a principal dificuldade imposta pela legislação ambiental, para manter os trabalhos nas agroindústrias Tabela 7 .

Tabela 7: Principais dificuldades impostas pela legislação ambiental para manter os trabalhos nas agroindústrias

\begin{tabular}{l|r|r|r|r}
\hline Alternativas & SEMA & SMMA & $\mathbf{N}^{\circ}$ total & \% total \\
\hline Não há dificuldades & 2 & 13 & 15 & 75 \\
\hline Excesso de exigências & 0 & 4 & 4 & 20 \\
\hline Entraves burocráticos & 1 & 0 & 1 & 5 \\
\hline
\end{tabular}

Fonte: Dados elaborados pelo autor. 
Através desses resultados pode-se concluir que $75 \%$ dos estabelecimentos não encontra nenhuma dificuldade quanto às questões ambientais, o que é muito significativo, já que as entrevistas foram realizadas em diversas localidades. Quanto ao excesso de exigências de alguns órgãos ambientais, como a contratação de um profissional (Engenheiro Químico ou Geólogo) responsável pela renovação da licença ambiental de operação, essa cobrança não procede, pois não existe nenhuma lei que exija a contratação de um destes dois tipos de profissional. Quanto à empresa que destacou os entraves burocráticos, se referindo à demora no desfecho desta documentação, essa situação pode ser em decorrência do acúmulo de documentação no órgão ambiental responsável, tendo como consequência à protelação para o seu despacho.

Já os resultados da questão referente aos custos, foi necessário calcular a média do valor anual pago para a renovação da licença ambiental de operação, já que em alguns municípios esta renovação pode ser anual, a cada dois anos, a cada três anos ou cada quatro anos Tabela 8.

Tabela 8: Custos referentes à questão ambiental para manter os trabalhos na agroindústria

\begin{tabular}{l|r|r|r|r}
\hline Alternativas & SEMA & SMMA & $\mathbf{N}^{\circ}$ total & \% total \\
\hline Não sabe & 0 & 4 & 4 & 20 \\
\hline Não há custo & 1 & 0 & 1 & 5 \\
\hline Até R\$ $1.000,00$ & 2 & 11 & 13 & 65 \\
\hline Entre R\$ $1.000,00$ e R $\$ 2.000,00$ & 0 & 2 & 2 & 10 \\
\hline
\end{tabular}

Fonte: Dados elaborados pelo autor.

Quanto aos custos, 20\% das empresas desconhecem os valores gastos com a renovação desta documentação, os demais estabelecimentos demonstram um bom controle administrativo das suas despesas, e através desses resultados é possível analisar a diferenciação desses valores, isso se deve aos diversos municípios que participaram deste trabalho.

\subsection{Segmento Tributário}

No segmento tributário foram encontrados nove estabelecimentos familiares que trabalham com registro e comercialização no sistema de Talão do Produtor e onze empresas com o Cadastro Nacional da Pessoa Jurídica (CNPJ).

$\mathrm{Na}$ segunda questão, resultados apresentados na Tabela 9, quando perguntados quais foram às principais dificuldades referentes à carga tributária imposta pela legislação para regularizar a agroindústria, das nove empresas registradas com o talão de produtor, sete afirmam que não tiveram nenhuma dificuldade quanto à carga tributária imposta pela legislação e apenas duas afirmam que os custos tributários são muito elevados se considerado o valor do 
alvará de funcionamento junto ao município de origem, custos com contador responsável, pagamento do Conselho Regional de Medicina Veterinária (CRMV) e a inexistência de diferenciação no pagamento de impostos entre as microempresas, o microprodutor rural, empresa de pequeno porte, empreendedor individual, empresa de médio porte e empresa de grande porte.

Contudo, das onze empresas registradas com CNPJ, oito afirmam que não tiveram dificuldade quanto à carga tributária imposta pela legislação e apenas três afirmam que os custos tributários são muito elevados. Da mesma forma dos outros estabelecimentos, considerando valores de alvará de funcionamento junto ao município de origem, custos com contador responsável, pagamento do CRMV e a inexistência de diferenciação no pagamento de impostos entre as microempresas, o microprodutor rural, empresa de pequeno porte, empreendedor individual, empresa de médio porte e empresa de grande porte Tabela 9.

Tabela 9: Principais dificuldades referentes à carga tributária imposta pela legislação no momento de registro das agroindústrias

\begin{tabular}{l|l|l|l|l}
\hline Alternativas & Talão de produtor & CNPJ & $\mathbf{N}^{\circ}$ total & \% total \\
\hline Não houve dificuldades & 7 & 8 & 15 & 75 \\
\hline Custo elevado no registro & 2 & 3 & 5 & 25 \\
\hline
\end{tabular}

Fonte: Dados elaborados pelo autor.

A diferenciação no pagamento de impostos no momento do registro entre os estabelecimentos de diferentes níveis estruturais não existe, essa alternativa poderia existir por ordem do poder público municipal, onde cada categoria empresarial pagaria uma determinada taxa de impostos, equivalente a sua metragem de construção. Em alguns casos, o microprodutor rural fica dispensado desses valores no momento que regulariza seu estabelecimento, isso depende da política administrativa de cada município. Quanto à taxa de pagamento ao CRMV, que é uma exigência cobrada por alguns órgãos de fiscalização, conforme o município onde o estabelecimento está inserido, o pagamento desta taxa é totalmente desnecessária e irregular, o estabelecimento não tem necessidade e obrigação de pagar este conselho, nenhuma legislação afirma a obrigação deste pagamento. Já os altos custos do alvará de funcionamento e os custos com o contador responsável, uma alternativa poderia ser a dispensa desses valores por parte das empresas, já que todos esses municípios futuramente arrecadarão impostos sobre os produtos comercializados. Essa alternativa serviria como forma de incentivo para os estabelecimentos que estão começando seus trabalhos.

Quanto aos custos referentes aos impostos que cada estabelecimento teve no momento do registro do estabelecimento, os dados estão apresentados na Tabela 10. 
Tabela 10: Custos referentes à questão da carga tributária no momento do registro das agroindústrias

\begin{tabular}{l|r|r|r|r}
\hline Alternativas & Talão de produtor & CNPJ & $\mathbf{N}^{\mathbf{0}}$ total & \% total \\
\hline Não sabe & 7 & 9 & 16 & 80 \\
\hline Não houve custo & 0 & 1 & 1 & 5 \\
\hline Até R\$ $1.000,00$ & 2 & 0 & 2 & 10 \\
\hline Acima de R\$ $1.000,00$ & 0 & 1 & 1 & 5 \\
\hline
\end{tabular}

Fonte: Dados elaborados pelo autor.

$\mathrm{Na}$ análise dos custos tributários de registro, pode-se apontar a falta de gestão da maioria dos estabelecimentos, onde estes locais não efetuaram nenhuma anotação destas despesas, ademais, os outros resultados mostram o controle que poucos estabelecimentos executam, bem como, a diferenciação desses valores, que podem variar conforme seus municípios de origem.

Na quinta questão, os responsáveis eram questionados sobre a principal dificuldade referente à carga tributária atual, que é imposta pela legislação para manter os trabalhos na agroindústria. Conforme a Tabela 11 os resultados são os seguintes.

Tabela 11: Principais dificuldades referentes à carga tributária para manter os trabalhos nas agroindústrias

\begin{tabular}{l|r|r|r|r}
\hline Alternativas & Talão de produtor & CNPJ & $\mathbf{N}^{\circ}$ total & \% total \\
\hline Não há dificuldades & 7 & 1 & 8 & 40 \\
\hline Diversidade de impostos & 0 & 2 & 2 & 10 \\
\hline Excesso de exigência & 0 & 1 & 1 & 5 \\
\hline Custo elevado & 1 & 7 & 8 & 40 \\
\hline Limitação na comercialização & 1 & 0 & 1 & 5 \\
\hline
\end{tabular}

Fonte: Dados elaborados pelo autor.

Pode-se observar nos resultados apresentados, dois extremos referentes às dificuldades tributárias, onde $78 \%$ dos estabelecimentos permitidos a comercializar com o talão de produtor não encontram nenhuma dificuldade quanto a este segmento, já as empresas que comercializam sob o sistema do CNPJ alegaram que o custo é muito elevado nas suas comercializações. Isso se deve a diferenciação entre os dois perfis empreendedores, onde as empresas com o talão do produtor não possuem nenhum custo quanto aos impostos de comercialização, conforme consta na lei $\mathrm{n}^{\circ}$ 10.045, (RIO GRANDE DO SUL, 1993), já as empresas com CNPJ são obrigadas a pagar impostos em cada comercialização. Porém esses locais ainda possuem uma diferenciação no custo desses impostos, que podem incidir sobre a quantidade de produto 
comercializado anualmente, isso se esses estabelecimentos estiverem cadastrados junto ao SIMPLES NACIONAL conforme a lei complementar $\mathrm{n}^{\circ}$ 123 (BRASIL, 2006). Alguns locais alegaram a inexistência de diferenciação entre impostos cobrados das pequenas, médias e grandes empresas, esta afirmação não procede, já que existe sim uma diferenciação entre esses custos, sendo todos equivalentes a quantidade de produto comercializado e ao perfil empreendedor do estabelecimento: microempresa, microprodutor rural, empresa de pequeno porte, empreendedor individual, empresa de médio porte e empresa de grande porte. Quanto à questão da exigência na emissão de nota fiscal eletrônica, isso demonstra a desqualificação dos responsáveis quanto às tecnologias de informática que estão em plena evolução, neste caso é importante destacar que o empresário deve se adaptar a essas novas tecnologias, para que assim não perca seu espaço no meio comercial. Já o estabelecimento que destacou a limitação na comercialização, fica claro o seu descontentamento no limite máximo de comercialização anual sem que incida a taxa de impostos, hoje esse limite é de 15.000 Unidade Padrão Fiscal (UPF) que representa R $206.130,00$, porém é importante ressaltar que estes locais estão em plena evolução e em um determinado momento deixam de ser microprodutores rurais para serem microempresas.

Quanto aos custos de impostos, foram destacados sobre o formato de porcentagem, pois esses valores são calculados em cima do valor do produto comercializado. Os resultados estão apresentados na Tabela 12.

Tabela 12: Custos referentes à carga tributária para manter os trabalhos nas agroindústrias

\begin{tabular}{l|r|r|r|r}
\hline Alternativas & Talão de produtor & CNPJ & $\mathbf{N}^{\mathbf{0}}$ total & \% total \\
\hline Não sabe & 1 & 4 & 5 & 25 \\
\hline Não há custos & 4 & 0 & 4 & 20 \\
\hline Até 5\% do valor do produto & 4 & 1 & 5 & 25 \\
\hline Entre 5\% e 10\% do valor do produto & 0 & 3 & 3 & 15 \\
\hline Acima de 10\% do valor do produto & 0 & 3 & 3 & 15 \\
\hline
\end{tabular}

Fonte: Dados elaborados pelo autor.

Sobre os custos dos impostos, algumas empresas desconhecem esses valores, com isso percebe-se que alguns locais não exercem nenhum controle administrativo neste segmento. Considerando que esses resultados são vivenciados quase diariamente e servem para planejar o futuro do estabelecimento, o conhecimento da situação tributária é considerado a mais importante para uma empresa, já que esse dado serve para identificar seus custos fixos e variáveis e a margem de lucro que pode incidir em cada comercialização. Algumas empresas que comercializam com o talão do produtor estão cientes que não possuem custos de impostos, outros estabelecimentos do mesmo 
perfil empreendedor, desconhecem essas condições e afirmam terem custos, possivelmente estes locais confundem o valor de 2,3\% cobrado em cada nota do talão emitida como um imposto sobre produto, esse valor é referente aos custos de previdência rural 2,1\%, Seguro de Acidente do Trabalho (SAT) 0,1\% e Serviço Nacional de Aprendizagem Rural (SENAR) 0,1\%, nos outros valores é possível observar as diferentes faixas dos custos de impostos, esses valores são definidos conforme os perfis empreendedores e as faixas de comercialização de cada estabelecimento.

\subsection{Segmento Sanitário}

No segmento Sanitário, foram estudadas dezesseis agroindústrias familiares registradas no Serviço de Inspeção Municipal (SIM) e quatro registradas na Coordenadoria de Inspeção Sanitária de Produtos de Origem Animal (CISPOA).

Quando perguntados quais foram às principais dificuldades referentes à questão sanitária no momento de regularizar a agroindústria, os resultados estão na Tabela 13.

Tabela 13: Principais dificuldades referentes à questão sanitária no momento do registro das agroindústrias

\begin{tabular}{l|r|r|r|r}
\hline Alternativas & Emp. SIM & Emp. CISPOA & $\mathbf{N}^{\mathbf{0}}$ total & \% total \\
\hline Não houve dificuldades & 12 & 2 & 14 & 70 \\
\hline Desinformação da fiscalização & 2 & 0 & 2 & 10 \\
\hline Excesso de exigência & 1 & 1 & 2 & 10 \\
\hline Entraves burocráticos & 1 & 1 & 2 & 10 \\
\hline
\end{tabular}

Fonte: Dados elaborados pelo autor.

Com estes resultados é possível observar que 70\% das empresas não encontraram dificuldade na questão sanitária para regularizar seus trabalhos, contudo devemos considerar que esta maioria está composta por estabelecimentos registrados junto ao SIM. Outros estabelecimentos ressaltaram a desinformação do órgão de fiscalização, isso pode ocorrer pela desqualificação profissional, ou a falta de pessoas qualificadas para prestarem a orientação correta. Outro item destacado foi o excesso de exigências, onde estão relacionados alguns casos de solicitação de reforma, que na concepção destes empresários era totalmente desnecessário naquela ocasião, neste caso devemos considerar que as pessoas envolvidas na fiscalização, são competentes para a realização deste serviço, já que estas exigências demandam de um corpo técnico especializado. Nesses casos existe uma grande importância para o estabelecimento, já que na maioria das vezes, para que seja feita a execução dessas exigências, é necessário uma reforma desses estabelecimentos, onde o 
responsável pelo local terá custos significativos para sua realização, por isso a importância de pessoas qualificadas nesta fiscalização. Foram destacados também os entraves burocráticos que muitas vezes dificultam o desfecho das documentações necessárias. A demora no retorno da documentação por parte do órgão sanitário responsável, muitas vezes está relacionado à dificuldade de mão de obra, bem como, o acúmulo de documentação proveniente de outras agroindústrias, sobre as diferenças políticas. Essas questões são casos isolados, tratados de forma particular e que podem ocorrer conforme os diferentes municípios.

Na Tabela 14 estão apresentados os resultados referentes aos custos sanitários que envolvem: registro junto ao órgão fiscalizador, registro de rótulo e produto, projeto técnico sanitário e a responsabilidade técnica, das empresas registradas pelo SIM.

Tabela 14: Custos referentes à questão sanitária no momento do registro das agroindústrias

\begin{tabular}{l|r|r|r|r}
\hline Alternativas & Emp. SIM & Emp. CISPOA & $\mathbf{N}^{\mathbf{0}}$ total & \% total \\
\hline Não sabe & 8 & 3 & 11 & 55 \\
\hline Não houve custo & 5 & 1 & 6 & 30 \\
\hline Até R\$ 1.000,00 & 2 & 0 & 2 & 10 \\
\hline Acima de R\$ $1.000,00$ & 1 & 0 & 1 & 5 \\
\hline
\end{tabular}

Fonte: Dados elaborados pelo autor.

Sobre os custos, $55 \%$ de empresas não têm conhecimento de quanto foi gasto para registrar seu estabelecimento junto ao órgão sanitário, isso demonstra a baixa capacidade das agroindústrias familiares em fazerem gestão dos seus estabelecimentos, pois não mantiveram qualquer tipo de registro desses valores, outras empresas que desenvolvem controle desta situação afirmam que não tiveram custo algum, pois o poder público do município de origem se responsabilizou em pagar estes valores, isso pode ser avaliado positivamente, pois serve de estímulo para o estabelecimento que está iniciando seus trabalhos, o restante das agroindústrias mantém um controle do que foi gasto, demonstrando a diferenciação desses valores, que podem variar conforme cada município.

$\mathrm{Na}$ próxima questão, que se refere à fiscalização sanitária, quando perguntados qual estava sendo a principal dificuldade referente à questão sanitária para manter os trabalhos nas agroindústrias, foram encontrados os resultados apresentados na Tabela 15. 
Tabela 15: Principais dificuldades referentes à questão sanitária para manter os trabalhos nas agroindústrias

\begin{tabular}{l|r|r|r|r}
\hline Alternativas & Emp. SIM & Emp. CISPOA & $\mathbf{N}^{\mathbf{0}}$ total & \% total \\
\hline Não há dificuldades & 15 & 0 & 15 & 75 \\
\hline Deficiência da fiscalização & 0 & 1 & 1 & 5 \\
\hline Entraves burocráticos & 0 & 1 & 1 & 5 \\
\hline Excesso de exigência & 1 & 1 & 2 & 10 \\
\hline Desinformação da fiscalização & 0 & 1 & 1 & 5 \\
\hline
\end{tabular}

Fonte: Dados elaborados pelo autor.

Diante destas respostas, é possível observar que $75 \%$ dos estabelecimentos não encontraram qualquer dificuldade quanto à fiscalização sanitária, é importante destacar que esta maioria é composta por estabelecimentos registrados junto ao SIM dos seus municípios de origem. Nas demais respostas, como a deficiência da fiscalização durante a matança, alegada pelas empresas que realizam este serviço, realmente o momento do abate só pode ser fiscalizado por um Médico Veterinário responsável, conforme consta no Art. 17 do Decreto ${ }^{\circ} 30.691$ (BRASIL, 1952) nesse caso devem ser tomadas medidas cabíveis de controle, através da exigência junto ao órgão sanitário responsável de profissionais competentes para a realização deste serviço. Quanto aos entraves burocráticos que se resumem na demora do retorno de algumas documentações para o estabelecimento, isso possivelmente ocorre devido aos vários documentos que se acumulam junto ao órgão sanitário responsável e a falta de mão de obra, cabe aos empresários ter paciência e aguardar o retorno. Aos estabelecimentos que destacaram o excesso de exigências, nesse caso é muito difícil definir o que isso significa, essa questão pode variar conforme a interpretação de cada pessoa, o certo é que cada solicitação do órgão sanitário, principalmente de reforma, teoricamente deve ser embasada em uma análise técnica estrutural de melhoria. Quanto à falta de informações, isso é uma questão administrativa do órgão sanitário de fiscalização, o que se pode concluir é que toda pessoa que está trabalhando nesta função é qualificada para transmitir informações corretas.

Quanto aos custos mensais, apresentados na Tabela 16, que são referentes ao responsável técnico, pela quantidade de produto produzido, análises de água e produto. 
Tabela 16: Custos referentes à questão sanitária para manter os trabalhos nas agroindústrias

\begin{tabular}{l|r|r|r|r}
\hline Alternativas & Emp. SIM & Emp. CISPOA & $\mathbf{N}^{\mathbf{0}}$ total & \% total \\
\hline Não há custos & 1 & 0 & 1 & 5 \\
\hline Até R\$ $1.000,00$ & 14 & 2 & 16 & 80 \\
\hline Entre R\$ 1.000,00 e R\$ 2.000,00 & 1 & 2 & 3 & 15 \\
\hline
\end{tabular}

Fonte: Dados elaborados pelo autor.

Quanto aos custos no segmento sanitário, pode-se observar que todas as empresas têm conhecimento e o controle administrativo de quanto é gasto mensalmente. Quanto ao estabelecimento que não possui custo, isso ocorre devido à competência que poder público municipal tem em pagar estes valores, este exemplo é positivo, pois serve de estímulo para o estabelecimento que está iniciando seus trabalhos.

\section{CONCLUSÃO}

Através deste trabalho pode-se analisar que as agroindústrias familiares nos três segmentos avaliados, encontraram as mais diversas dificuldades e estas podem variar conforme o órgão de fiscalização que a empresa está inserida.

Quanto aos custos, pode-se avaliar a grande diferença de valores desembolsados entre cada empresa, se comparado a cada segmento, e que por muitas vezes variam devido a uma série de questões, principalmente correlacionadas ao perfil do estabelecimento.

Com esses resultados apontados, algumas questões ficam evidentes entre os estabelecimentos. Apesar da maioria desses locais terem um grande tempo de experiência, podemos destacar o desconhecimento sobre as legislações vigentes, sobre as técnicas agroindustriais, os custos administrativos e a gestão geral das empresas. Os motivos para esse desconhecimento pode estar relacionado a questões como o baixo grau de escolaridade dos entrevistados, profissionalização dos responsáveis na área de alimentos e o recebimento ou não de assistência técnica.

Está claro que a família agrícola ainda não está preparada para fazer gestão das suas agroindústrias, necessitando receber orientações nas áreas administrativas e técnicas de seus estabelecimentos. Uma maior atenção profissional junto a estes estabelecimentos pode resolver grande parte dessas dificuldades.

\section{REFERÊNCIAS}

BRASIL. Decreto $\mathrm{n}^{\circ}$ 30.691, de 29 de março de 1952. Aprova o novo Regulamento da Inspeção Industrial e Sanitária de Produtos de Origem Animal. Diário Oficial da 
União, Rio de Janeiro, RJ, 29 mar. 1952. Disponível em: http:/ / extranet.agricultura. gov.br/sislegis-consulta/consultarLegislacao.do?operacao=visualizar\&id=14974. Acesso em: 04 jan. 2013.

BRASIL ${ }^{2}$, Lei Complementar $\mathbf{n}^{\circ} \mathbf{1 2 3}$ de 14 de dezembro de 2006. Institui o Estatuto Nacional da Microempresa e da Empresa de Pequeno Porte. Diário Oficial da União, Brasília, DF, 15 dez. 2006. Disponível em: http:/ / www.receita.fazenda.gov.br/ Legislacao/LeisComplementares/2006/leicp123.htm. Acesso em: 02 jan. 2013.

RIO GRANDE DO SUL. Resolução CONAMA n 385, de 27 de dezembro de 2006. Estabelece procedimentos a serem adotados para o licenciamento ambiental de agroindústrias de pequeno porte e baixo potencial de impacto ambiental. Diário Oficial do Estado, Porto Alegre, RS, 27 dez. 2006. Disponível em: http:/ / www.mp.rs. gov.br/ambiente/legislacao/id4976.htm. Acesso em: 17 fev. 2013.

FREIRE, Paulo. Extensão ou comunicação?. Tradução de Rosisca Darcy de Oliveira; Prefácio de Jaques Chonchol, $7^{a}$ ed. Rio de Janeiro, Paz e Terra, 1983. 93p.

KUHN, Fábio. TUDO. 3. ed. Lajeado - Rio Grande do Sul: Revista A hora do vale. 2012.

\section{RIO GRANDE DO SUL. Lei $\mathbf{n}^{\circ} \mathbf{1 0 . 5 8 4}$, de 24 de novembro de 1995.}

Introduz alterações na Lei $\mathrm{n}^{\circ} 10.045$, de 29 de dezembro de 1993, que estabelece tratamento diferenciado às microempresas, aos microprodutores rurais e às empresas de pequeno porte. Diário Oficial do Estado, Porto Alegre, RS, 24 nov. 1995. Disponível em: http:/ /www.al.rs.gov.br/legis/M010/M0100099.ASP?Hid_Tipo=TEXTO\&Hid_ TodasNormas=11802\&hTexto=\&Hid_IDNorma=11802. Acesso em: $21 \mathrm{fev} .2013$

SANTOS, Renato Cougo dos. Agroindústria Familiar Rural Base Legal. Disponível em: <www.emater.tche.br/site/br/arquivos/area/agroindustria/Base $\% 20$ Legal\%20 Agroindustria\%20Familiar.pdf>. Acesso em: 20 fev. 2013. 